\title{
HACIA LA CONSTRUCCION DE UNA TEORIA DE LA INTERPRETACION: EN TORNO AL DEBATE HABERMAS-GADAMER
}

Ricardo Montoro Romero

\section{Introducción: ¿Hermenéutica para qué?}

Hace ya algunos siglos, cuando las mejores fuerzas intelectuales y de pensamiento humanas tenían que dirimir cuestiones teológicas, o al menos interpretaciones teologizantes de la siempre preocupante realidad -curiosa y felizmente puede afirmarse que siempre lo mejor del humano intelecto se ha orientado a la explicación de su realidad-, hubo que interpretar la Biblia como texto ordenador de reinos humanos. Muchos más siglo atrás, el inefable y contradictorio pueblo griego echó mano del baúl mitológico para hacer uso de un dios que comunicaba a los hombres con el intrincado y alejado mundo de los dioses: Era Hermes, el mensajero alado de los dioses. Era el principio - mitológico, como casi todo lo humano- de la interpretación de las cosas; las naturales y las otras.

Hermes, yaciendo en la etimología de la palabra hermenéutica, nos remonta a la gravedad y profundidad del tema de la interpretación. Realmente, lógicamente, resulta difícil tocar fondo en un asunto de tamaño calibre. No es de extrañar, pues, que una y otra vez a lo largo de los siglos, y ahora una vez más, con igual fuerza, resucite con virulencia para recordar al hombre 
que no es fácil interrumpir el diálogo - chumillante? - que sostiene -y quizá deba sostener - con el mensajero alado.

Hoy, la hermenéutica, la vieja hermenéutica, está viva gracias sobre todo al impulso de Gadamer. Cuando su «Verdad y Método» vio la luz por primera vez en 1960, Gadamer abrió la posibilidad de una discusión en torno a los problemas básicos de la ciencia de lo social desde unas perspectivas contemporáneas. Por su lado, Habermas, heredero inmediato de la tradición germana de la Teoría Crítica, vendría a entrar en la discusión desde una posición en la que pretende desarrollar aquella tradición con mejor o peor fortuna. El impacto que estas dos personalidades intelectuales produjeron en la década de los setenta ha sido considerable. Se han sucedido encuentros y mesas redondas a lo ancho y largo del mundo occidental. Consecuentemente, la bibliografía suscitada en torno al tema es ya importante. Y, precisamente, en este contexto es donde se sitúa este trabajo. En las páginas siguientes, entraremos a analizar críticamente el contenido de esta polémica en algunos de sus aspectos más interesantes. No obstante, debemos señalar de antemano que el asunto no es sencillo, dadas las características de las distintas posiciones. Hay muchos puntos de conexión que ocultan los de divergencia, y viceversa.

En las siguientes líneas intentaremos un ejercicio de reflexión que oscilará entre lo analítico y lo crítico. Ejercicio que, probablemente, sea en sí mismo el ejemplo más elocuente de las pretensiones - mayores o menores, logradas o no- de una labor interpretadora.

\section{Comprensión y lenguaje}

El tema de la comprensión -y utilizamos aquí el término castellano que, bien es cierto, poca precisión consigue, como veremos inmediatamente- está en el sustrato mismo de una reflexión hermenéutica. Tamaña vinculación no es nueva: se remonta a la tradición exegética bíblica, y pasa a través de las escuelas filológica e histórica, aunque ciertamente con características diferentes en cada momento. Desde un principio, la dicotomía básica será «comprensión-interpretación». Dos conceptos fundamentales que serán relacionados de forma diferente según el pensador de turno. Dos conceptos que, habría que decir, tienen que aguardar la llegada de Schleiermacher para adoptar un planteamiento científico moderno.

No se trata aquí de hacer un estudio histórico-comparativo. Pero, de cara a nuestro objetivo, sí puede ser interesante que destaquemos el uso que hace Droysen dentro de la llamada escuela histórica. Droysen ${ }^{1}$, siguiendo las hue-

1 Droysen parece haber sido, en opinión de Georg Henrik von Wright, el primero en plantear con coherencia científica la dicotomía metodológica: explicación (erklären)-comprensión (verstehen). Droysen, originariamente, desarrolló esta diferenciación metodológica como tricotomía, a saber: 
llas de Humboldt, alude al proceso de la comprensión como una búsqueda indefinida. Quizá lo más relevante del planteamiento de Droysen sea la estricta diferenciación que establece entre los mundos de la Naturaleza y de la Historia, empleando quizá por primera vez dos métodos diferentes y contrapuestos: a) explicar (erklären), y b) comprender (verstehen). El primero de ellos es el propio de las ciencias de la naturaleza, frente al segundo que corresponde a las ciencias del espíritu o morales. Esta distinción entre mundos diferentes tuvo una especial significación y éxito al ser recogida tanto por Dilthey como por Weber. El «verstehen», esa comprensión que se da en las ciencias morales, no tiene como objetivo la determinación cuantitativa de los fenómenos —que, de cualquier forma, aquí serían históricos, o del espíritu, en contraposición con los fenómenos naturales-, sino que su labor consiste realmente en comprender los acontecimientos que protagoniza el hombre. $\mathrm{O}$, de otra manera, investigar los elementos que son necesarios para poder comprender al ser humano. $Y$ comprenderlo significa aquí comprenderlo en todas sus manifestaciones artísticas, sociales, etc. Se trata, en definitiva, de que el hombre en la historia busca reconocerse a sí mismo. Esta idea, robustecida y replanteada continuamente a lo largo del siglo XIX, tuvo un impacto considerable $\mathrm{y}$ ha conducido a jugosos plänteamientos contem. poráneos.

El problema de la comprensión así planteado fue, sigue y seguirá siendo fundamental cuando de bases metodológicas científicas se trate ${ }^{2}$. Es, sobre todo desde Max Weber, la eterna pregunta que ronda la cabeza del científico social sobre cuál sea el objetivo de un conocimiento adecuado, tanto en el ambiguo terreno de las ciencias sociales como incluso en las ciencias de la naturaleza. Vuelven aquí una y otra vez los dos viejos temas que espolearon a los pioneros de la institucionalización de la Sociología como-ciencia social válida; a saber, a) la definición del hecho social, y $b$ ) el enojoso asunto de la predicción en el terreno de lo social ${ }^{3}$.

La hermenéutica contemporánea, sobre todo con Gadamer, contempla a la comprensión y la interpretación como dos momentos distintos de una misma totalidad. Este principio, que de alguna manera generalizada se ha ido afianzando a lo largo del siglo $\mathrm{xx}$, nos parece lo suficientemente adecua-

$$
\begin{array}{lllllllllll}
\text { Método filosófico } & \ldots & \ldots & \ldots & \ldots & \ldots & \ldots & \ldots & \ldots & \text { conocer (erkennen) } \\
\text { Método físico } & \ldots & \ldots & \ldots & \ldots & \ldots & \ldots & \ldots & \ldots & \text { explicar (erklären) } \\
\text { Método histórico } & \ldots & \ldots & \ldots & \ldots & \ldots & \ldots & \ldots & \ldots & \text { comprender (verstehen) }
\end{array}
$$

(G. H. voN WRIGHT, Explicación y comprensión, Alianza Ed., Madrid, 1979, pág. 23).

2 En el terreno de la más reciente producción hispana, habría que citar como ejemplo elocuente de lo que afirmamos el trabajo de Miguel Beltrán, Ciencia y Sociologia, Centro de Investigaciones Sociológicas, Madrid, 1979; en especial, los primeros apartados del segundo capitulo.

${ }^{3}$ Resulta siempre preclaro el extraordinario análisis que Parsons hace de Weber y sus planteamientos metodológicos. Vid. especialmente TalcotT PARsons, La estructura de la acción social, Ed. Guadarrama, Madrid, 1968, 2. vol., páginas 713 y sigs. 
do como para plantear el tema ${ }^{4}$. Nosotros, siguiendo con el discurso lógico que iniciamos en este apartado, entraremos a reflexionar acerca de esa «interpretación preliminar»; o, más generalmente, como el «círculo hermenéutico», la enigmática base del tema hermenéutico.

Con el viejo planteamiento hermenéutico de Schleiermacher, que posteriormente pasaría al historicismo de Droysen y a las ciencias del espíritu de Dilthey, aparece claramente «una estructura circular por cuanto lo singular debe ser entendido en el todo, pero el todo también en lo singular. La comprensión de lo singular presupone, pues, una precomprensión del todo dentro del cual es comprendido; pero la comprensión del todo crece de la comprensión de los momentos singulares que se estructuran en la totalidad" ". Una vez sentado esto, el asunto queda reducido a ver cuál pueda ser esa totalidad. $\mathrm{Y}$ varias han sido, según las distintas versiones: $\mathrm{El}$ "contexto histórico» en Droysen; la «unidad de vida de la que brotan las exteriorizaciones singulares como 'objetivaciones de la vida'» en Dilthey; el "mundo de vida», de Husserl; o como «totalidad de naturaleza del 'ser en el mundo'», en Heidegger ${ }^{6}$. Sea como fuese, considerando siempre una estructura circular en la intelección.

Pero centrémonos en Gadamer y en lo que denomina el «descubrimiento de la preestructura de la comprensión» realizado por Heidegger ${ }^{7}$. Gadamer describe de la siguiente manera el proceso que llevó a cabo Heidegger: a la búsqueda de una «interpretación correcta», el intérprete debe «orientar su mirada 'a la cosa misma' (que en el filólogo son textos con sentido que tratan a su vez de cosas)... (Tiene que) dejarse determinar así por la cosa misma ( $y$ eso no es) sino verdaderamente 'la tarea primera, constante y última'. Pues lo que importa es mantener la mirada atenta a la cosa aún a través de todas las desviaciones a que se ve constantemente sometido el intérprete en virtud de sus propias ocurrencias. El que quiere comprender un texto realiza siempre un proyectar — continúa Gadamer-. Tan pronto como aparece en el texto un primer sentido, el intérprete proyecta en seguida un

${ }^{4}$ Aunque prácticamente no hablamos en este trabajo de la diferencia existente entre los conceptos de "comprensión" e "interpretación", sí debemos señalar al menos que el problema de la vinculación o diferenciación de ambos está en el origen cronológico del planteamiento hermenéutico, sin que haya recibido una solución acogida por todos los que han reflexionado sobre este asunto. Gadamer, y ésta es la explicación que tenemos por no haber hecho previamente esta distinción, concibe la interpretación, la comprensión, así como un tercer elemento que es la "aplicación", como los "tres momentos hermenéuticos", sin que exista una diferencia explícita o analítica. "La interpretación -dice Gadamer- no es un acto complementario y posterior al de la comprensión, sino que comprender es siempre interpretar, $y$ en consecuencia la interpretación es la forma explícita de la comprensión" (Verdad y método, Ed. Sígueme, Salamanca, 1977, pág. 378 y passim).

' Emerich Coreth, Cuestiones fundamentales e hermenéutica, Ed. Herder, Barcelona, 1972, pág. 108.

- Ibídem, pág. 109.

7 Hans-Georg Gadamer, Verdad y Método, op. cit., págs. 331 y sigs. 
sentido del todo. Naturalmente que el sentido sólo se manifiesta porque ya uno lee el texto desde determinadas expectativas relacionadas a su vez con algún sentido determinado». Comprender lo que dice el texto «consiste precisamente en la elaboración de este proyecto previo", que necesita ir siendo revisado constantemente de acuerdo con los resultados que se vayan obteniendo cuando «se avanza en la penetración del sentido». La tarea constante de la comprensión de Heidegger, concluye Gadamer, consiste en «elaborar los proyectos correctos y adecuados a las cosas, que como proyectos son anticipaciones que deben confirmarse 'en las cosas'»"

Pero si de lo que se trata es de que todo intérprete que quiera explicar algo - ya sea un texto o una cosa - tenga que partir de una especie de terreno de «comprensión previa o supuesta», de "pre-comprensión», o de «pre-interpretación», en el que el supuesto intérprete debe "pre-comprender» tanto el tema concreto como la situación en la que se desenvuelve ese tema; si de lo que se trata es de que el que va a comprender baya comprendido ya «de qué va la cosa», y posea una suerte de comprensión parcial que le sirva para comprender cada vez más allá, entonces surge aquí al menos un problema que debe preocuparnos: ¿Tienen las ciencias del espíritu -a lo Dilthey-, o las ciencias sociales - a lo Weber- algún criterio de defensa que afirme que lo que se pre-comprende no es puramente arbitrario; que no operen sola y exclusivamente criterios de la más pura subjetividad, con lo que no podría llegarse jamás a un criterio de objetividad sobre lo que se comprende? $\mathrm{Y}$ aún podriamos plantear aquí otro gran problema que, como tendremos ocasión de contemplar más tarde, reaparecerá con virulencia cuando veamos el desarrollo contemporáneo de la hermenéutica de Gadamer evolucionando frente a otras corrientes de pensamiento. Como muy bien ha señalado Hirsch ${ }^{9}$, en el concepto «interpretación» hay que apreciar un momento adivinatorio que siempre está presente. Pero existe además un momento crítico, que es el encargado de llevar las hipótesis de interpretación al nivel del conocimiento. Pero aunque el planteamiento nos parece sumamente eficaz y correcto, si el criticismo hace su aparición con plena legitimidad, tendremos que averiguar precisamente qué es ese «momento crítico». Es decir, sus características y límites. Porque las distintas -y sutiles - apreciaciones que de él se hagan son las que obstaculizan sabiamente y en última instancia los encuentros de la nueva hermenéutica gadameriana con los planteamientos de Habermas, quien, como ya dijimos, representa a una corriente de pensamiento que ha incorporado el adjetivo a su misma denominación.

Con esto, no hacemos sino adelantar —quizá demasiado precipitadamente- un problema que seguramente ni siquiera podremos resolver al concluir este trabajo. Digamos, eso sí, que la hermenéutica de Gadamer, con el

Ibídem, pág. 333.

9. D. HIRsch, Validity in interpretation, Yale University Press, 9." ed., 1979, págs. $X$ y sigs. 
fin de intentar remover los dos obstáculos que hemos presentado, huye de subjetivismos y pretende diseñar un criterio de objetividad que sea válido. Con él, la crítica —aquel momento crítico de la interpretación- tendrá una base sustentadora muy apreciable.

Pero antes de seguir adelante para encontrar nuevos elementos de argumentación que ya vamos necesitando, conviene que nos detengamos, aunque sea brevemente, para abordar un asunto que entra a fondo en aquel otro de la interpretación y que ha sido planteado por la hermenéutica de Gadamer de una forma casi reivindicatoria. Nos referimos al «prejuicio», que anida en aquel difícil y voluble estadio de pre-comprensión. Gadamer, con un análisis sumamente brillante, intentará buscar la objetividad incluso en ese estadio de la mano del prejuicio.

Efectivamente, la importancia de este elemento es tal que, según Gadamer, «sólo este reconocimiento del carácter esencialmente prejuicioso de toda comprensión confiere al problema hermenéutico toda la agudeza de su dimensión» ${ }^{10}$. Gadamer está luchando contra el uso y conceptualización de la Ilustración, tan cuidadosa de su Razón, hizo del prejuicio, otorgándole un carácter negativo que, según Gadamer, no tiene. Porque, «en sí mismo, 'prejuicio' quiere decir un juicio que se forma antes de la convalidación definitiva de todos los momentos que son objetivamente determinantes (...). Prejuicio no significa, pues, en modo alguno, juicio falso, sino que está en su concepto el que pueda ser valorado positiva o negativamente (...). (Hay en la palabra) junto al matiz negativo, también un matiz positivo»".

Gadamer se enfrenta, pues, con la Razón de la Ilustración, que pretendía protegerse de esa manera de los prejuicios. Y así, partiendo de la existencia humana, Gadamer ofrece un nuevo criterio de razón: "¿No es cierto, más bien, que toda existencia humana, aun la más libre, está limitada y condicionada de muchas maneras? Y si esto es así, entonces la idea de una razón absoluta no es una posibilidad de la humanidad histórica. Para nosotros la razón sólo existe como real e histórica; esto es, la razón no es dueña de sí misma, sino que está siempre referida a lo dado en lo cual se ejerce» ${ }^{12}$. $\mathrm{Y}$ es así, concluye Gadamer, cómo «los prejuicios de un individuo son, mucho más que sus juicios, la realidad histórica de su ser» ${ }^{13}$.

Hemos visto, sucintamente, la concepción básica de comprensión hermenéutica que, vía Dilthey y Heidegger, llega hasta Gadamer. Hasta el momento, no obstante, no hemos aludido a la primordial dimensión lingüística que tienen los esfuerzos de los hermeneutas al uso de Gadamer. Nos interesa

10 H. G. Gadamer, op. cit., pág. 337.

"Ibídem.

12 Ibídem, pág. 343.

43 Ibidem, pág. 344. Cfr. también un texto de 1966 en el que Gadamer reafirmaba su posición: "No son tanto nuestros juicios cuanto nuestros prejuicios lo que constituyen nuestro ser" (Philosophical Hermeneutics, University of California Press, 1976, pág. 9 y passim). 
ahondar un poco más profundamente en las concepciones de comprensión con el fin de situar mejor el tema. Para ello, recurriremos a la distinción que Habermas, proveniente de la teoría crítica, establece entre tres tipos diferentes de comprensión, aunque interrelacionados entre sí. A saber:

a) Comprensión lingüística (sprachverstehen).

b) Comprensión mutua (verständigtsein).

c) Comprensión hermenéutica (verstehen) ${ }^{14}$.

Para Habermas, cuando se habla de hermenéutica y comprensión, hay que diferenciar entre esas tres esferas, contemplando la relación a que están sometidas -interrelación sería más correcto-, sin caer en la supeditación de una sobre otra, que es lo que, en definitiva, de acuerdo con Habermas y siguiendo su esquema diferenciador, busca Gadamer. En este planteamiento, la esfera que Habermas califica como «más amplia» es la primera, o sea la lingüística. Pero ésta no puede ser concebida aisladamente, ni mucho menos, sino que necesitará de la segunda - la «comprensión mutua», sobre la que descansa el complejo mundo de la comunicación humana- para basarse y sustentarse en ella.

Hasta aquí, esquemáticamente y sobre el papel, no surgen mayores problemas, si ambas esferas se corresponden y asisten mutuamente. Pero los problemas están presentes. Siempre lo han estado, y continúan estándolo. Ya se encargan las diferentes disciplinas de señalarlos: la política, la sociología, la lingüística. $\mathrm{Y}$ estos problemas, que en definitiva son de comunicación, que proceden sustancialmente del mal ajuste -entre otras causas- de aquellas dos primeras esferas, y que se plasman en lo que Habermas ha denominado como «comunicación distorsionada»; esos problemas, pues, son los que hacen necesaria la existencia de la tercera esfera, el recurso al "verstehen". Y aquí es donde, en opinión de Habermas, debe enmarcarse y desarrollarse la tradición hermenéutica.

Es decir, para Habermas la principal tarea que la hermenéutica debe llevar a cabo - y también la que más le caracterizará- es intentar solucionar los problemas de comunicación que surjan dentro de un mismo lenguaje -y ello básicamente, sin menospreciar la importante labor que la hermenéutica desempeña en el difícil tema de la traducción de lenguaje a lenguaje, tema éste que dejaremos de lado en este trabajo.

El «verstehen», por lo tanto y para Habermas, ni se vincula exclusivamente con el lenguaje, ni reduce en él mismo el complejo estudio de los sistemas sociales o de la sociología; en definitiva, el estudio de la sociedad, que deberá realizarse sin que quede reducido exclusivamente a una tarea de hermeneutas.

14 JÜrgen Habermas, Zur Logik der Sozialwissenschaften, Suhrkamp Verlag, F. am M., 1970, pág. 254. 
Habermas está basando su argumentación en el concepto de «competencia comunicativa», que define de la manera siguiente: como «la capacidad del hablante nativo de participar comprendiendo y hablando, en comunicaciones en el lenguaje ordinario» ${ }^{15}$. $\mathrm{Y}$ si la hermenéutica y la comprensión (verstehen) desempeñan su papel en el tratamiento de la competencia comunicativa, no lo hacen en tanto que ciencia del lenguaje o como lingüística, puesto que «también se distingue la hermenéutica de la ciencia del lenguaje». Así, «la hermenéutica hace referencia $(.$.$) a experiencias del hablante en$ esa dimensión (la dimensión pragmática en que 'langue' se convierte en 'parole'). Además, la lingüística tiende a una reconstrucción del sistema de reglas que permite la producción de todos los posibles elementos - correctos desde el punto de vista gramatical y llenos de sentido desde el punto de vista semántico- de un lenguaje natural, mientras que la hermenéutica refleja experiencias básicas de un hablante competente desde el punto de vista comunicativo (cuya competencia lingüística se presupone tácitamente)» ${ }^{16}$.

Habermas está diferenciando entre la «reconstrucción racional» — propia de la gramática-, y la «autorreflexión»-característica de la hermenéutica, así como utilizada, de modo ciertamente diferente, por él mismo-. En esa distinción, Habermas afirma: "Por la vía de la autorreflexión, un sujeto llega a aclararse sobre los supuestos inconscientes de los actos que ha realizado. Así, la consciencia hermenéutica es el resultado de una autorreflexión en la que el sujeto hablante se percata de su peculiar libertad y dependencia del lenguaje. Con ello, se diluye la ilusión, tanto subjetivista como objetivista, en la que está prendida la consciencia ingenua. La autorreflexión esclarece experiencias que le ocurren al sujeto hablante en el uso de su competencia comunicativa, pero no puede explicar esa competencia.» Mientras que «la reconstrucción racional de un sistema lingüístico de reglas sirve, en cambio, a la explicación de la competencia lingüística. Explicita las reglas que el hablante nativo domina implícitamente, pero no trae propiamente a la consciencia del sujeto supuestos inconscientes. La subjetividad del hablante - añade Habermas-, cuyo horizonte es la única sede posible de la experiencia de la reflexión, queda fundamentalmente ausente (...). La consciencia del hablante no se modifica, en efecto, por este saber lingüísticon" ${ }^{17}$.

Con todo esto, Habermas está siguiendo y perfilando lo ya contenido

is J. Habermas, La pretensión de universalidad de la hermenéutica, en prensa. Nosotros nos referiremos, de ahora en adelante, a un ejemplar multicopiado del que en esta nota aludimos a la pág. 9. La traducción castellana corresponde al original alemán Der universalitätsanspruch der hermeneutik, en $\mathbf{K}$. O. APEL y otros, Hermeneutik und Ideologiekritik, F. a. M., 1971. Traducido al castellano por Modesto Saavedra y Mariano Maresca. Del primero puede consultarse también un importante trabajo titulado Interpretación del Derecho e ideologia. Elementos para una crítica de la hermenéutica juridica, Universidad de Granada, 1978.

${ }^{16}$ Ibídem. En este punto, Habermas está aludiendo concretamente al trabajo de Noam Chomsky, y a su creación de un hablante ideal.

17 Ibídem, pág. 10. 
en los viejos teóricos críticos. Es decir, partiendo de la necesaria unión existente entre lenguaje y sociedad, la estrecha vinculación entre el concepto y el lenguaje; la recuperación, en definitiva, del «logos apofántico» de Aristóteles que Marcuse utilizara hace ya algunos años: un tipo especial de logos que no es sino la palabra, la comunicación, y que a su vez será lo que descubre lo verdadero y lo falso, y lo que a su vez está determinado por ello ${ }^{18}$.

\section{Lenguaje y tradición}

Como ya indicamos, Gadamer ha recogido buena parte de la herencia hermenéutica en nuestros días. Su aportación - como ya vimos al hablar del "círculo hermenéutico" - tiene muchos elementos de los que existieran ya en Heidegger. En esa misma línea está su concepto de comprensión hermenéutica, según el cual sólo se comprende un texto, o un asunto, o una situación teniendo y partiendo de una pre-concepción, de la llamada preestructura de comprensión.

De esta manera, va a suponer Gadamer, si lo que queremos es comprender algo que ocurre en el presente, sólo lo podremos hacer a través del cúmulo complejo de intenciones, perspectivas diversas, y múltiples pre-concepciones que se pueden extraer del pasado.

Pero, ¿qué es ese pasado? ¿Cuál es su conexión con el presente, y si cabe, con el futuro? El pasado - y ésta es una de las principales y más enojosas tesis de Gadamer- no es algo ya fenecido; no es una «gran pila de hechos consumados». Al contrario, el pasado se nos ofrece a modo de torrente en el que nos movemos y en el que participamos. El pasado entendido como «fuente» o «manantial»; idea ésta que también rige para el presente: He aquí la estrechísima vinculación que los une. $Y$ así es cómo el pasado toma cuerpo bajo la forma de la tradición. Tradición hecha por lo humano, que se manifiesta como un torrente, y que, por tanto, no se enfrenta en absoluto con estos otros humanos que hacen el presente: en ella estamos y a través de ella existimos ${ }^{19}$.

1* En este caso concreto, me estoy refiriendo a H. Marcuse, El hombre unidimensional, Alianza Ed., Madrid, 1972, págs. 158 y passim (la edición original inglesa es de 1954). En la misma línea, y aunque nosotros no nos detendremos en este punto, es útil la referencia a T. W. Adorno y M. HorkeImer, Sociológica, Ed. Taurus, Madrid, 1971, especialmente págs. 278 y passim (el original es de 1962). $\mathbf{E}$ igualmente a T. W. AdorNo, La ideologia como lenguaje, Ed. Taurus, Madrid, 1971, especialmente págs. 55 y passim (el original alemán es de 1962-64).

$19 \mathrm{La}$ influencia hegeliana es fuerte tanto en Habermas como en Gadamer. Conviene reseñar aquí, si se quiere como simple anécdota, que esa idea de tradición de Gadamer coincide con la de Hegel cuando alude a ella no como "una estatua inmóvil, sino como una corriente viva (que), fluye como un poderoso río cuyo caudal va creciendo a medida que se aleja de su punto de origen". Y concluye Hegel: "El contenido de esta tradición es lo que ha creado el mundo espiritual" (Lecciones sobre la historia de la filosofía, FCE, México, 1977, vol. I, pág. 9). 
Esta concepción del tiempo, que tan importante es para el Gadamer hermeneuta, busca en última instancia un «distanciamiento temporal» que se parece mucho al «distanciamiento estético» - no en balde toda la primera parte de su gran obra, «Verdad y Método», está dedicada a buscar la verdad desde la experiencia del arte ${ }^{20}$ - El tiempo, pues, y concibiendo de tal forma a la tradición, está ahí no para amortiguar nuestros intereses personales, que surgen cuando estudiamos un tema. Todo lo contrario: opera de la forma en que lo hace para eliminar lo que no es esencial, con el fin de conseguir que el verdadero significado del tema - es decir, de las cosas, del texto que analizamos, etc.-, significado que podría estar oculto en la enmarañada hojarasca del momento que fue presente, aparezca claramente, eliminando todo aquello que no es esencial. Y utilizando estos conceptos, asi es cómo Gadamer define la compresión hermenéutica: «El comprender debe pensarse menos como una acción de la subjetividad que como un desplazarse uno mismo hacia un acontecer de la tradición, en el que el pasado y el presente se hallan en continua mediación. Esto es lo que tiene que hacerse oír en la teoría hermenéutica, demasiado dominada por la idea de un procedimiento, de un método" ${ }^{21}$.

Con ello, como acabamos de ver, no se trata de hacer un nuevo método de la ciencia hermenéutica - a lo Dilthey-, ni tan siquiera a lo Heidegger -el método fenomenológico, la «hermenéutica de la facticidad», basada en la pertenencia del sujeto humano al mundo, y no viceversa-. Aquí es apreciable una vez más la franca superación de Gadamer. El papel de la hermenéutica, pues, no es desarrollar un procedimiento metódico que nos permita adentrarnos en la comprensión de las cosas con una mayor confianza. Su tarea consiste en poner en claro las condiciones bajo las cuales debe darse esa comprensión, que es algo bien diferente. Y ello bien entendido que lo que realmente preocupa al intérprete que escudriña —un texto, por ejemplo-, no es interpretar el sentimiento, o la opinión, o «lo que movió» al autor del mismo exactamente. El intérprete, en su labor de interpretación, se busca a sí mismo como sujeto.

No se puede perder de vista que la gran obra de Gadamer está orientada al reasentamiento del «verstehen» de las ciencias humanas en nuestro mundo actual ${ }^{22}$. «El poder real de la conciencia hermenéutica —afirma Gadamer- es nuestra capacidad para discernir lo que es cuestionable». $\mathrm{Y}$ para resolver el

${ }^{20}$ Cfr., asimismo, Verdad y Método, op. cit., pág. 660.

21 Ibídem, págs. $360 \mathrm{y}$ sigs.

22 Sumamente interesante resulta la contraposición crítica que Gadamer realiza entre estadística y hermenéutica, concediendo a esta última un papel fundamental. Más concretamente, y refiriéndose al terreno de la metodología científica, Gadamer critica profundamente lo que él denomina "obvias esterilidades metodológicas" que hacen que una ciencia se centre en un objeto de investigación que no merezca la pena, sencillamente porque no se ha empezado con una pregunta simple y genuina. Una pregunta que, naturalmente, es difícil y que es propia del terreno hermenéutico (Philosophical Hermeneutics, op. cit., págs. 10-11). 
viejo asunto de las ciencias del hombre de averiguar «cuál es la cuestión», para ello hace falta imaginación (Phantasie) ${ }^{23}$.

Con todo esto, la comprensión hermenéutica para Gadamer parece reducirse a un simple proceso subietivo, cuyo único fin sería colocarnos a nosotros mismos -en cuanto sujetos- en el marco de la tradición. Y es en este punto donde Gadamer introduce un inteligente giro con el fin de salvar el difícil escollo de lo objetivo en las ciencias del hombre: Para Gadamer, el sujeto que realiza el proceso hermenéutico de comprensión, además de buscarse a sí mismo en él -a sí mismo en cuanto hombre que vive un determinado momento histórico-, está participando en el torrente de la tradición en un momento en el que presente y pasado se entremezclan. Por tanto, $y$ en consecuencia, el punto de referencia real de todo el proceso hermenéutico no es la subjetividad del autor del texto - seguimos con el ejemplo- que se estudia; ni tan siquiera lo es el lector que interpreta. El punto de referencia último es el significado histórico que para nosotros tiene el presente que habitamos. «Cada época - dice Gadamer- entiende el texto transmitido de una manera peculiar, pues el texto forma parte del conjunto de una tradición por la que cada época tiene un interés objetivo y en la que intenta comprenderse a sí misma. El verdadero sentido de un texto tal como éste se presenta a su intérprete no depende del aspecto puramente ocasional que representan el autor y su público originario. $\mathrm{O}$, por lo menos, no se agota en esto. Pues este sentido está siempre determinado también por la situación histórica del intérprete, y en consecuencia por el todo del proceso histórico" ${ }^{24}$.

Esta interpretación del proceso hermenéutico, entendiéndolo bajo el prisma del momento histórico, no quiere decir tampoco que el trabajo del hermeneuta deba ser la reconstrucción del pasado; reconstrucción entendida aquí también como recreación - «crear por segunda vez»- de algo que en un momento anterior fue original. Para Gadamer, la labor de la hermenéutica no es la de restaurar nada, sino la de integrar; es decir, una labor de integración en el proceso histórico que hemos denominado tradición. Y, para ello, cuenta con dos excelentes armas, desarrolladas ampliamente en la actualidad y en diversas disciplinas, y que Gadamer maneja a la perfección; éstas son, en primer lugar, el lenguaje--entendido como forma en la que se manifiesta la tradición-; y, en segundo término, la dialéctica y el diálogo dialéctico, como forma que debe adoptar la comprensión hermenéutica ${ }^{25}$.

${ }^{23}$ Ibídem, págs. 12 y 13.

24 Gadamer, Verdad y Método, op. cit., pág. 366.

${ }^{25}$ Puede verse un excelente planteamiento de la dialéctica platónica y del diálogo socrático en Gadamer, Verdad y Método, op. cit., págs. 439 y sigs. Asimismo, para ver este tema con más atención de la que mostramos nosotros aquí, puede consultarse el excelente análisis comparativo que Oliva Blanchetre realiza de las concepciones del diálogo como comunicación en "Language, the primordial labor of history: A critique of critical social theory in Habermas", en Cultural Hermeneutics, 1, febrero 1974, especialmente págs. 332 y sigs. 
Esta «recuperación» tan bien elaborada que la hermenéutica de Gadamer hace con la historia, a la búsqueda de una reformulada vinculación de la misma con el complejo mundo de las ciencias humanas, es uno de los puntos que llevan a Habermas a reflexionar sobre la hermenéutica. Podría decirse, incluso, que esa preocupación por la historia —en el caso de Habermas, usando de un materialismo en línea marxista ${ }^{26}$ - es uno de los puntos comunes que existen en el diálogo hoy mantenido entre Gadamer y Habermas.

La dependencia existente, tan bien señalada por Gadamer, de la «comprensión que interpreta» con respecto a la «situación inicial» del intérprete, es tal que desvela perfectamente la naturaleza profundamente histórica de ese intérprete. $\mathrm{Y}$ esto, que para Gadamer es uno de los grandes éxitos de la hermenéutica, obliga a replantear y repensar las complejas relaciones que unen a la teoría que se esconde en las ciencias del hombre con la historia -o con la filosofía de la historia, como veremos a continuación-. Relaciones éstas que, según Habermas, habían sido al menos puestas en cuestión en los últimos tiempos. "Actualmente - argumenta Habermas- la opinión predominante es que las ciencias sociales se han alejado de la jurisdicción de las ciencias del espíritu y han encontrado una relación con la historia que no plantẹa problemas. Las teorías generales de la acción social son, por así decirlo, perpendiculares al complejo histórico de la tradición. La sociología... procede con indiferencia respecto de la historia. Elabora sus datos sin tener en cuenta el contexto específico; la posición histórica de los datos aparece neutralizada desde un comienzo. Para la sociología, toda historia ha devenido presente (...). Está proyectada en el plano de la simultaneidad y así ha hurtado su espíritu real» ${ }^{27}$.

$\mathrm{Ni}$ en Gadamer ni en Habermas cabe concebir una sociedad que esté «liberada» de la historia. Por tanto, tampoco cabe una interpretación - sea cual fuere- que no entable un diálogo fructífero con la historia, ni concebir, en última instancia, una sociedad que se encuentre liberada de la interpretación del contexto cuando nos encontramos dentro de una situación histórica precisa. Hay amplia coincidencia en este importante aspecto. Pero esa coincidencia debe ser matizada, sobre todo cuando hay que responder a la siguiente comprometida pregunta: ¿Qué hay detrás de ese concepto de historia o de tradición, de acuerdo con las distintas vertientes?

Desde la perspectiva de Gadamer, ya hemos indicado anteriormente que la comprensión hermenéutica posee una intrínseca característica de temporalidad, que se traduce en contemplar e interpretar el mundo en términos de tradición, de pasado y presente. Pero la comprensión tiene otra característica

${ }^{26}$ Sobre el materialismo histórico de Habermas y su interpretación del marxismo de la mano de la herencia de la teoría crítica puede verse mi artículo "La reconstrucción del materialismo histórico de Jürgen Habermas", Revista Española de Investigaciones Sociológicas, núm. 12, octubre-diciembre 1980.

${ }_{27} \mathrm{~J}$. Habermas, Zur Logik..., op. cit., pág. 93. Cita recogida en Thomas McCarTHY, The critical theory of Jürgen Habermas, The MIT Press, 1979, pág. 178. 
fundamental, que, por cierto, también será extensible a la tradición; nos estamos refiriendo a la lingüisticidad: «No sólo el objeto preferente de la comprensión, la tradición, es de naturaleza lingüística; la comprensión misma posee una relación fundamental con la lingüisticidad ${ }^{28}$. Y ello es de tal manera que, aduce Gadamer, «reconocemos como tarea nuestra el ganar la comprensión del texto sólo desde el hábito lingüístico de su tiempo o de su autor» ${ }^{29}$.

Nuestro conocimiento histórico, nuestra conciencia histórica, para Gadamer, es lingüística en sí misma. Y no sólo eso: también la experiencia, el pensamiento $\mathrm{y}$, por supuesto, la comprensión son lingüísticos a su vez. Lingüísticos, pero ¿con respecto a qué concepto de lenguaje?

No tiene Gadamer una concepción del lenguaje en tanto que forma simbólica - a lo Cassirer ${ }^{30}$ - . Gadamer contempla el lenguaje como el «medium» en el que yace almacenada y hasta oculta la experiencia que todo pueblo histórico va acumulando. Lógicamente, pues, el lenguaje es un medio inseparable tanto de la experiencia como de la existencia ${ }^{31}$. Con esta lógica, dice Gadamer, «nuestra reflexión ha estado guiada por la idea de que el lenguaje es un centro en el que se reúnen el yo y el mundo; o mejor, en el que ambos aparecen en su unidad originaria" ${ }^{32}$.

Cierto es, y eso no se le escapa a Gadamer, que el lenguaje tiene una importante forma simbólica. Pero también tiene un contenido, y si su forma es signo o simbolismo, no es eso precisamente lo que es capaz de definir al lenguaje. De la misma suerte, el lenguaje, que es algo tan humano - genuinamente humano, habría que decir-, no pertenece al hombre exactamente, en la medida en que el hombre, ya previamente, ya desde el principio, pertenece a su contexto. Habrá que concluir, por consiguiente, que el lenguaje pertenece más propiamente a la situación —en la que ya está el hombre-. Es decir, que nosotros, los humanos del presente que interpretamos y comprendemos, cuando recurrimos al lenguaje no buscamos sino las palabras que ya pertenecen a la situación; porque con la situación nos topamos, y ésta tiene ya sus palabras de las que nosotros no hacemos sino servirnos - sin olvidar, por supuesto, que nosotros somos y estamos también en esa situación-. «El ser que puede ser comprendido es lenguaje —arguye Gadamer-. El fenómeno hermenéutico devuelve aquí su propia universalidad a la cons-

${ }^{28}$ Gadamer, Verdad y Método, op. cit., pág. 475.

29 Ibidem, pág. 334.

${ }^{30}$ Vid. una excelente discusión del tema en Verdad y Método, op. cit., páginas 485 y sigs.

31 Gadamer, con esta concepción tan amplia del lenguaje, está siguiendo -aunque siempre con fuertes aires críticos y superadores- el clasicismo de la hermenéutica de los siglos xviu y xIx. No en vano coloca a modo de epígrafe encabezador de la tercera, última y fundamental parte de su libro - Verdad y Métodouna cita de Schleiermacher que simplemente reza como sigue: "Todo lo que hay que presuponer en la hermenéutica es únicamente lenguaje".

32 Ibídem, pág. 567. 
titución óntica de lo comprendido cuando determina ésta en un sentido universal como lenguaje, y cuando entiende su propia referencia a lo que es como interpretación. Por eso no hablamos sólo de un lenguaje del arte, sino también de un lenguaje de la naturaleza, e incluso del lenguaje de las cosas» ${ }^{33}$.

Nosotros, en nuestra experiencia y nuestro pensamiento, no encontramos las palabras del lenguaje mediante un acto reflexivo. Todo lo contrario: Cuando formulamos una afirmación usamos las palabras que pertenecen a la situación. «En realidad - afirma Gadamer - en la formación de la palabra no opera reflexión alguna. La palabra no expresa al espíritu sino a la cosa a la que se refiere. El punto de partida de la formación de la palabra es el contenido objetivo mismo que llena el espíritu. El pensamiento que busca su expresión no se refiere al espíritu sino a la cosa. Por eso la palabra no es expresión del espíritu sino que se dirige hacia la cosa (...). La palabra interior del espíritu no se forma por un acto reflexivo. El que piensa o se dice algo, se refiere con ello a lo que piensa, a la cosa (...). La interioridad de la palabra, en la que consiste la unidad íntima de pensar y hablar, es la causa de que se ignore tan fácilmente el carácter directo e irreflexivo de la 'palabra' ${ }^{34}$.

El lenguaje y las palabras, después de lo dicho, y en la concepción de Gadamer, quedan muy léjos de ser unos simples instrumentos de la subjetividad y la reflexión humanas. Porque, además, si bien es cierto que el lenguaje tiene una forma simbólica - que es inseparable del contenido-, el contenido no es ni más ni menos que toda la transmisión histórica humana - aquello que denominábamos el torrente de la tradición.

$\mathrm{Y}$ aún podemos señalar dos características importantes además de lo ya dicho. En primer lugar, que puesto que el lenguaje no tiene el fácil carácter de instrumento que le adjudican otras escuelas, sino que en la concepción de Gadamer aparece como «medium», tampoco podrá ser captado jamás como «hecho», ni por tanto objetivizado totalmente. Importante conclusión ésta, que permite a Gadamer utilizar con la flexibilidad necesaria este fundamental elemento.

$Y$, por otro lado, existe una segunda característica del lenguaje que debe anotarse aquí, sobre todo después de lo que acabamos de decir acerca del carácter no-reflexivo del lenguaje: y es su estructura intrínsicamente especulativa. Sobre esto, afirma Gadamer: «Especulativo aquí lo mismo que ocurre con el reflejo de un espejo. Reflejarse a sí mismo es una especie de suplantación continua. Algo se refleja en otra cosa, el castillo en el estanque, por ejemplo, y esto quiere decir que el estanque devuelve la imagen del castillo. La imagen reflejada está unida esencialmente al aspecto del

3 Ibidem, págs. 567-8. El subrayado se encuentra en el original.

${ }^{34}$ Ibídem, pág. 511. El subrayado se encuentra en el original. 
original a través del centro que es el observador (...). Es como una duplicación que, sin embargo, no es más que la existencia de uno solo.» Y continúa más adelante: «Especulativo es lo contrario del dogmatismo de la experiencia cotidiana $(\ldots)$. Y una idea es especulativa cuando la relación que se enuncia en ella no puede pensarse como atribución inequívoca de una determinación a un sujeto, de una propiedad a una cosa dada» ${ }^{35}$.

«Lo que puede comprenderse es lenguaje - concluye Gadamer-. Esto quiere decir: Es tal que se presenta por sí mismo a la comprensión. La estructura especulativa del lenguaje se confirma también desde este lado. Acceder al lenguaje no quiere decir adquirir una segunda existencia» ${ }^{36}$.

\section{El encuentro de la bermenéutica con la teoria critica de la sociedad}

Como se recordará, cuando hablábamos de definir $\longrightarrow$ mejor sería decir situar - la hermenéutica, lo hacíamos no considerándola como «un problema filosófico más», precisamente. En la difícil tarea de la comprensión e interpretación, el recurso a la hermenéutica es fundamental. Y qué duda cabe que existe un peliagudo problema de interpretación en el dificultoso terreno de las ciencias de la sociedad -recordemos simplemente y una vez más la preocupación de Weber-. Y no olvidemos tampoco que reiteradamente Gadamer ha indicado que la tarea que debe cumplir la hermenéutica es tanto la de evitar malentendidos como la de trascender los prejuicios que tan bien diseñara el mismo Gadamer, prejuicios que delimitan la conciencia estética, la conciencia histórica y hasta a la misma hermenéutica, para así superar en definitiva el cúmulo de alienaciones que subyugan al individuo ${ }^{37}$.

Esta es la razón de fondo por la que, en las formulaciones que nos son contemporáneas, la hermenéutica es un tema a considerar y estudiar cuando de lo que se trate sea de hacer una teoría de la sociedad. Esto es, precisamente, lo que ha llevado a Habermas a polemizar en el asunto: La necesidad -aunque sea en última instancia - de lograr una interpretación de la sociedad.

El planteamiento básico ha sido captado certeramente por Habermas: Las ciencias sociales, ultra-desarrolladas en nuestro siglo $\mathrm{xx}$, generan en su tarea unos datos. $Y$ será la vida cotidiana, con su lenguaje ordinario y con su sentido común - más o menos sofisticados- la que los interpretará de alguna forma. De alguna forma que necesariamente será parcial o partidista.

$\mathrm{La}$ acción social -eso tan importante y que tantos quebraderos de cabeza ha dado a los sociólogos de múltiples tendencias-; las relaciones sociales, siempre complejas y dificultosas de captar; todas ellas realidades so-

3s Ibidem, págs. 557-8.

${ }^{36}$ Ibidem, pág. 568.

37 Cfr. Gadamer, Philosophical Hermeneutics, op. cit., págs. 15 y 8. 
ciales, tienen lo que Habermas denomina con mucho acierto un carácter «intencional». $\mathrm{Y}$ las ciencias sociales, además de procurarse los datos que describen, tienen que encontrarse en disposición de captar aquellas otras dimensiones de la misma realidad. Para captarlas pueden usarse distintos caminos: Bien optar por el lenguaje ordinario, cercano al sentido común, pero que permita reflexionar científicamente; bien buscar un metalenguaje para encontrar la precisión y justeza que con el lenguaje ordinario están en peligro. Sea como fuese, con lenguaje ordinario o sin él $-\mathrm{y}$ de esto sabe mucho la lingüística de nuestros días-, lo que sí es necesario es un procedimiento de interpretación -metódico o no- de cierto empaque y alcance.

Justo ahí, en ese procedimiento de interpretación, es donde encaja el lenguaje, y así hay que entenderlo en los tratamientos de Gadamer, Wittgenstein, Chomsky, o, por supuesto, Habermas.

Gran parte de la crítica que Habermas formula sobre Gadamer se fundamenta en la absolutización que el último realiza tanto del lenguaje como de la tradición. Demostrar que eso necesita un sustrato idealista es uno de los principales objetivos de Habermas.

La importancia de la hermenéutica contemporánea, y en especial la que elabora Gadamer, es incuestionable para Habermas. Sobre todo, porque ha señalado con la precisión que nuestros días necesitan el hecho de que la comprensión humana se desenvuelve dentro de un contexto-límite históricamente preciso y que no se debe olvidar. Entre sus logros figura la superación de la vieja escisión ciencias naturales-ciencias del espíritu, con la consiguiente eliminación de la «autocomprensión objetivista» que caracterizaba a las ciencias del espíritu tradicionales tal y como las planteara Dilthey. La nueva hermenéutica de Gadamer ofrece ahora una nueva y sugestiva noción de objetividad; como ya hemos visto, cuando aquí se habla de «interpretar un significado» - ya sea de una palabra o de un texto-, esa interpretación no se limita a un subjetivismo, sino que, con los ingredientes de la tradición, historia, lenguaje, etc., Gadamer está preparado para referirse a una nueva objetividad - siempre diferente, ni que decir tiene, a la propia del mundo de la naturaleza- ${ }^{38}$. La hermenéutica, afirma Habermas, ha puesto de manifiesto con una especial fuerza y de nuevo que en las ciencias sociales «los problemas que surgen en el plano de la medición, retornan en el plano de la formación de teorías» ${ }^{39}$.

Pero, siguiendo a Habermas, el lenguaje tiene su sitio, y pretender convertirlo en el eje central cuando se habla de la «forma de vida» y de la tradición es un importante error que comete Gadamer. Error, porque responde a un planteamiento claramente idealista, ya que «existe una premisa que dice: Una conciencia articulada lingüísticamente determina el significado ma-

${ }^{36}$ Vid. J. HABermas, La pretensión..., op. cit., pág. 11. Puede verse el acertado planteamiento de Th. MCCARTHY, The critical..., op. cit., pág. 183 y passim.

${ }^{39}$ J. Habermas, La pretensión..., op. cit., pág. 12. 
terial de la actividad de la vida». Determinación, consecuentemente, idealista. Cuando lo que sucede, en opinión de Habermas, es que «el sistema objetivo de la acción social no se ve confinado en la dimensión de la intersubjetividad y el significado transmitido simbólicamente». Porque, aunque es cierto que el lenguaje posee un contenido que es distinto de la forma simbólica que le caracteriza, efectivamente habrá que indagar acerca del «significado» que porta dicho lenguaje -o sea, su contenido- Lo cierto es, afirma $\mathrm{Ha}$ bermas, que «la intraestructura lingüística de una sociedad es un momento de un sistema tal que, aunque exista una mediación simbólica, está también constituido por las exigencias de la realidad: La exigencia de la naturaleza externa que surge en el proceso del control técnico, y la exigencia de la naturaleza interior reflejada en las represiones de las relaciones en el terreno de la dominación social. (De esta forma) la Sociología no puede reducirse a sí misma a ser simplemente interpretadora» ${ }^{40}$.

En este sentido, argumenta Habermas, es cierto que Gadamer ha encontrado esa "nueva objetividad» en su hermenéutica. Pero, dentro del terreno sociológico —en su más alto sentido-, esa hermenéutica tiende a constreñir lo que mueve al inquirir sociológico, con lo que, en definitiva, la labor interpretadora de este último se reduce a la explicación -aunque no en el sentido de las ciencias naturales diltheyanas- de un significado que, para hacerlo más problemático todavía, se manifiesta como lenguaje. De esta forma, los procesos sociales, en la interpretación hermenéutica, aparecen subsumidos dentro de la tradición, que aparece aquí como un concepto más amplio que los orienta y les da sentido. Esos procesos sociales aparecen como desgajados, y para estudiarlos hay que hacer forzosamente estudio de tradición. La sociología, y las ciencias sociales en términos generales, quedan reducidas a la interpretación del contenido de esa tradición. Y eso, concluye Habermas, es algo demasiado breve y limitado.

La tradición de Gadamer es, fundamentalmente, de indole cultural -siempre entendiendo ese cultural en sentido sumamente lato-. Bajo esa forma, tradición ya es lenguaje. ¿Y qué hay del conjunto de condiciones reales y objetivas de tipo social, económico y político? ¿Cómo abordarlas? $\mathrm{Si}$, en definitiva, de lo que se trata es de que la sociología - y por extensión las ciencias sociales- queden reducidas a una mera «interpretación del sentido» (Sinnverstehen), a «verstehen» pues, ello sólo es justificable si se usan hipótesis idealistas como las que Gadamer utiliza: Hipótesis que afirmen que la conciencia articulada lingüísticamente determina las condiciones materiales de vida ${ }^{41}$.

La acción social —en el sentido más genérico- requiere para Habermas un marco objetivo. O de otra forma, se da la acción social en la intersubjetividad - sobre la que, por cierto, se basa la teoría de la comunicación

to J. Habermas, Zur Logik..., op. cit., pág. 289.

"I Esta es la tesis mantenida por McCarthy, op. cit., pág. 184. 
habermasiana-, sin que esa acción social se agote en tamaña subjetivadad, ni tampoco en un significado que, en el torrente de la tradición, es transmitido simbólica y lingüísticamente. Ese marco está, de hecho, mediado simbólicamente, pero fundamentalmente está constituido de acuerdo con las exigencias de una realidad - que en Habermas toma las formas de naturaleza externa (técnica) e interna (intersubjetividad y comunicación)—. Es definitiva, afirma Habermas, «la acción social sólo puede ser comprendida en un marco objetivo que viene constituido conjuntamente por lenguaje, trabajo y dominación (Herrschaft)» ${ }^{42}$.

Esas son las tres esferas que determinan la acción social. Pero sin el predominio del lenguaje que caracteriza a Gadamer. «Las dimensiones del trabajo y la dominación —afirma Habermas - no pueden ser suprimidas en favor de contenidos simbólicos de carácter subjetivo... (Así es cómo) la tradición cultural pierde la apariencia de un absoluto que le otorga falsamente una hermenéutica autosuficiente. La tradición como un todo puede verse situada en el sitio que le corresponde; puede ser concebida en relación con los sistemas de trabajo social y dominación política" ${ }^{43}$.

Observemos aquí una diferencia en el matiz, que es ampliamente subrayada por Habermas: Los desarrollos que experimentan las esferas del trabajo y la dominación están mediados lingüísticamente, sin que pueda decirse que sean lingüísticos. Es decir, dentro de aquellas dos esferas existen múltiples e importantes dimensiones que, sin ser lingüísticas, pueden modificar su manifestación lingüística por razones que, evidentemente, no pertenecen al terreno del lenguaje. Con ello, Habermas se está refiriendo, por ejemplo, a las modificaciones que pueden sufrir el modo de producción, o los sistemas de relaciones de poder.

De esta forma, para Habermas el procedimiento de interpretación que supone la hermenéutica de nuevo cuño es sumamente importante, como ya tuvimos ocasión de señalar en su momento, por la misma constitución de la realidad social que hay que estudiar. Pero, de cualquier forma y en eso estamos de acuerdo con Habermas, la hermenéutica no puede ser más que el prolegómeno de una teoría general de la sociedad, teoría que puede y debe ser más amplia y que sobrepasa el planteamiento de la mera hermenéutica. Es decir, el «verstehen», la comprensión hermenéutica, nos sirve para dar paso a una teoría social más amplia, que incorpore más y distintos elementos que el lenguaje, donde queden considerados tanto el lenguaje como la tradición y el prejuicio de Gadamer, pero sin ser absolutizados.

42 J. Habermas, Zur Logik..., op. cit., pág. 289. Cita recogida por McCarthy, op. cit., pág. 184. Ver aquí también el interesante comentario hecho por el autor.

${ }^{43}$ J. Habermas, ibídem, pág. 305. Cita recogida por MCCARTHY, ibídem, pág. 183. El subrayado pertenece al original. 
Concluyentemente, para Habermas la hermenéutica no es capaz de desempeñar su papel si no viene acompañada de otros tres elementos fundamentales:

a) La crítica de la ideología.

b) El análisis de los sistemas sociales.

c) La historia o la filosofía de la historia.

El objetivo a lograr en el primero de los casos es, abiertamente, «desabsolutizar» la tradición de Gadamer, puesto que la crítica de la ideología aquí Habermas está recogiendo el legado de la teoría crítica - necesita un sistema de referencia que vaya más allá de la tradición. Con el segundo de los elementos, hay que proceder al análisis sistemático de los sistemas sociales, puesto que es ése el objetivo válido de las ciencias sociales. Y la filosofía de la historia, no entendida de manera contemplativa, como teoría cerrada que dice tener un futuro abierto, servirá para conectar al actor social del presente con su capacidad de proyectar o anticipar el futuro. Es el caso de una proyección práctica o anticipación del futuro - una vez más en clara continuidad con lo característico de la vieja escuela crítica- basada en las determinaciones reales que existen en la sociedad del presente, es decir, analizando y desarrollando el presente.

\section{A modo de conclusión}

A lo largo de las anteriores páginas, nos hemos asomado con brevedad a una polémica que está en marcha. La hermenéutica, hoy día, está siendo fundamental en los esfuerzos que las ciencias de la sociedad se toman para conseguir una interpretación de lo que en ese extraño y difícil mundo social ocurre en cada momento. Como ya dijimos en otro momento, el temá de fondo es viejo y enraizado en la misma definición de las ciencias del hombre. G. H. von Wright lo ha visto muy bien: «Si se acepta una demarcación metodológica fundamental entre las ciencias naturales y las Geisteswissenschaften históricas, surgirá inmediatamente la cuestión de dónde situar a las ciencias sociales y a las ciencias de la conducta. Estas ciencias nacieron en buena medida bajo la influencia de una presión cruzada de las tendencias positivista y antipositivista del último siglo. No es sorprendente por lo tanto el que hayan venido a resultar un campo de batalla para las dos tendencias en liza en la filosofía del método científico» ${ }^{4}$.

En torno a la polémica hermenéutica (Gadamer)-teoría crítica (Habermas), a la que nos hemos ceñido en este trabajo, habría que decir muchas más cosas; porque también se han dicho muchas y más variadas a lo largo

4 Explicación y comprensión, op. cit., pág. 25. 
de toda la década de los sesenta. El tema, como resulta obvio, sigue abierto ${ }^{45}$. Abierto con un amplio pórtico por el que se han colado escepticismos soberbios acerca de la misma autenticidad de semejante controversia. Citemos, por su especial agudeza, la crítica de Bubner ${ }^{46}$; e incluso en este capítulo habría que referirse igualmente a Gadamer, quien en 1967 llega a hablar de la existencia de una coincidencia con Habermas, aunque fuese al menos porque no se aprecian claras incompatibilidades entre las dos posiciones ${ }^{47}$.

Ello no obsta para que los principales interesados en esta polémica -a saber, Gadamer y Habermas- se hayan criticado a fondo y mutuamente a lo largo del tiempo. Quizá la acusación más importante formulada por $\mathrm{Ha}$ bermas sobre Gadamer, como ya hemos tenido ocasión de ver, sea la de que en este último, y pese a su «empirismo radical» que no puede ponerse en duda, existe una fuerte y necesaria carga idealista ${ }^{48}$. Idealismo que reposa en la sobre-valoración del lenguaje en sus distintas formas. La reflexión hermenéutica, para Habermas, no puede validarse como reflexión lingüística en última instancia, tal y como pretende Gadamer; sino que aquella reflexión sólo puede ser desarrollada auténticamente dentro de un concepto de reflexión crítica más amplio, que incorpore las tres esferas que vimos líneas arriba.

${ }^{45}$ En el mundo anglosajón y de plena actualidad, tenemos que referirnos aquí a dos importantes trabajos en torno a esta polémica, ambos inéditos y de próxima aparición: THOMAS McCARTHY, Rationality and relativism: Habermas "overcoming" of hermeneutics, y MARTIN JAY, Should intellectual history take a linguistic turn? Reflections on the Habermas-Gadamer debate.

Ya en el terreno del castellano, conviene destacar el artículo de José LuIs García de la Serrana, Racionalidad y Política (1979, ejemplar multicopiado), y la reciente aparición del libro de RAúl GaBás, Jürgen Habermas: Dominio técnico y comunidad lingüística, Ariel, 1980, una importante aportación al conocimiento de este pensador en nuestro país. De señalar también es el prólogo que acompaña al libro, escrito por Javier Muguerza, otro buen conocedor y crítico de Habermas (vid., por ejemplo, su La razón sin esperanza, Ed. Taurus, Madrid, 1980, páginas 141-174).

* Nos referimos a la excelente crítica realizada por RÜDIGER BuBNER en su "Theory and practice in the light of the hermeneutic-criticist controversy," Cultural Hermeneutics 2, 1975, págs. 337 a 352 , especialmente págs. 338 y sigs., para el que el desacuerdo existente entre Gadamer y Habermas es más una pseudocontroversia que otra cosa, debido a que, metodológicamente hablando, la diferencia existente es perfectamente salvable. Bubner llama la atención sobre el hecho de que tanto Gadamer como Habermas estén reclamando para sí la ostentación genuina del criticismo. $Y$ hace bien Bubner en preguntarse, después de analizar lo contenido en uno y otro argumento: "pero ¿qué es lo crítico? ¿Y con respecto a qué?".

${ }^{77}$ Vid. Gadamer, Philosophical Hermeneutics, op. cit., pág. 31.

${ }^{48} \mathrm{Cfr}$. el excelente análisis crítico que Albrecht Weillmer, un hombre muy cercano a Habermas, realiza en su "Comunications and emancipation: Reflections on the linguistic turn in critical theory", contenido en el libro de JoHN O'NExLL (Ed.), On critical theory, The Seabury Press, N. Y., 1976, especialmente las páginas 254 y sigs. 
Gadamer le responderá que eso es mal comprender a la hermenéutica, ya que toda situación que exige el esfuerzo hermenéutico de comprensión es ya de por sí crítica: La necesidad de comprender mejor no se realiza ni a través de la interacción simple del yo individual con el grupo, ni a través de una visión simplista - como la que Habermas parece tener- de la tradición. Las situaciones hermenéuticas tal y como Gadamer las diseña implican de modo natural evaluaciones críticas continuas. La reflexión hermeméutica, por lo tanto, es crítica forzosamente. Quizá más: Es auténticamente crítica, y en absoluto idealista - ahí está la tradición para demostrarlo-. Es precisamente la «actividad reflexiva» de los llamados críticos - como Habermas- la que muestra palpablemente su idealismo, puesto que de ella, del puro pensamiento en definitiva, quieren extraer el cambio del mundo. $Y$ esto, realmente, es algo que lo tiene todo menos la novedad y la aportación.

Gadamer se sitúa en una de las posiciones más comprometidas - y atractivas- de toda la tradición de las ciencias sociales cuando acusa a Habermas de sobreestimar el pensamiento filosófico que yace en la realidad social a través de la presuposición de que la razón es tanto o más poderosa que la siempre engorrosa emoción, y perdiendo por tanto en la interpretación un elemento que, por difícil que sea su análisis, eso no hace más que señalar nuestra impotencia analítica y nunca su escasa importancia ${ }^{79}$. «En mi opinión - dice Gadamer- no puede haber comunicación ni reflexión en absoluto sin una base previa de acuerdo común. Por el contrario -continúa-, la teoría crítica sugiere, que ya no existe un terreno común para gentes de diferentes orientaciones políticas: Tan enorme es el grado de deformación del lenguaje que aliena a la gente. Por lo tanto, el acuerdo sobre conceptos básicos tales como humanismo o democracia es imposible. La teoría crítica asegura que estos conceptos claves para la vida social pueden ser reestablecidos únicamente a través de un discurso crítico que desenmascare el impacto de intereses - despóticos, capitalistas, burocráticos- sobre la formación de convicciones comunes. Tal es el programa de la crítica de la ideología. Sin embargo, ¿es válido como tal?» Más adelante, Gadamer continúa: «Mi objeción es que la crítica de la ideología sobreestima la competencia de la reflexión y la razón (...). En la medida en que el lenguaje (speech) y la comunicación sean posibles, el acuerdo parecería ser posible también. Naturalmente, ello no quiere decir que pueda lograrse dicho acuerdo al primer intento. La comunicación demanda siempre un continuo intercambio de perspectivas y situaciones. En cualquier caso, presupone que existen convicciones comunes que uno puede descubrir y desarrollar dentro de un acuerdo más amplio. Consecuentemente, no puedo compartir las tesis de la teoría crítica según las cuales uno puede dominar el proceso de nuestra civilización a través de la reflexión emancipadora. Uno debería ser consciente, es cierto, de que existen siempre

". Vid. Gadamer, Verdad y Método, op. cit., págs. 659 y sigs. 
precondiciones dentro de una organización y práctica sociales que nos impiden comprendernos unos a otros. Y ésa es precisamente la noble tarea de la hermenéutica: Hacer consciente expresamente tanto lo que nos separa como lo que nos une a los demás» ${ }^{50}$.

El interés de la cita compensa con creces la desaforada extensión de la misma. En ella pueden apreciarse sintetizadamente algunos de los principales aspectos en litigio.

Pese a todo, el debate sigue abierto, y probablemente lo seguirá estando algún tiempo más. La disputa ya no tiene las características de crasa incompatibilidad que eran propias de la polémica germana cronológicamente anterior, protagonizada por Popper y Adorno. Por nuestra parte, podemos afirmar que, efectivamente, hay muchos puntos comunes en ambas posiciones. $Y$ queremos reconocer en el esquema habermasiano la posibilidad de superar los problemas de profundo corte idealista que se derivan de la lingüisticidad hipostasiada de Gadamer, y del uso del concepto de tradición tal como en él queda formulado. La hermenéutica, a la hora de formular una teoría de la interpretación convincente, es una excelente ayuda para desentrañar el confuso terreno de la precomprensión, del prejuicio y del mundo social de esa dificultosa emoción a la que aludía Gadamer. Pero todo ello dentro de una teoría de la sociedad más amplia y compleja, donde las relaciones de poder o económicas no quedan reducidas - ni conceptual ni analí. ticamente- a esencias lingüísticas.

Es decir, una teoría de la interpretación exige hoy día una teoría de la sociedad. Pero igualmente cierto es el hecho de que esa siempre difícil teoría de la sociedad no puede perder de vista los espinosos problemas de la interpretación y comprensión -que a su vez se expresan con amplio espectro en formas lingüísticas, de comunicación, de definición del hecho social, o de ideologías puras y simples- si no quiere caer en los viejos errores del modelo ultra-empirista.

Curiosamente, y todavía a estas alturas del siglo $\mathrm{xx}$, puede decirse que estamos al comienzo de una carrera. Aunque sea la carrera de eliminar lo anquilosado y lo enmohecido: De ahí, como han visto muchos visionarios del futuro -incluyendo a Gadamer- puede salir ese mismo futuro.

30 Gadamer, "Hermeneutics and social science", Cultural Hermeneutics 2, 1975, pág. 315. Este número de la citada revista recoge las sesiones de una mesa redonda celebrada en el Boston College, en abril de 1974, en torno al tema Hermenéutica y Teoría Crítica, y con participación de destacados especialistas en la materia. 